\title{
Improved Tomato Fruit Color within an Inbred Backcross Line Derived from Lycopersicon esculentum and $L$. hirsutum Involves the Interaction of Loci
}

\author{
Eileen Kabelka, Wencai Yang, and David M. Francis ${ }^{1}$ \\ Department of Horticulture and Crop Science, The Ohio State University, Ohio Agricultural Research \\ and Development Center, 1680 Madison Avenue, Wooster, OH 44691
}

\begin{abstract}
AdDitional INDEX words. inbred backcross, CIELAB color space, quantitative trait loci (QTL), molecular markers, epistasis
AbStract. An inbred backcross (IBC) population derived from Lycopersicon hirsutum LA407 and L. esculentum was evaluated in replicated field trials to assess its potential for the improvement of red-fruited tomatoes. Significant phenotypic variation among genotypes was detected for the hue (tint), L (darkness), and chroma (saturation) of color. Significant effects due to environment and genotype $x$ environment interactions also were observed. One superior inbred backcross line from this population, IBL 2349, was used to develop an $F_{2}$ population and to explore the genetic basis of color. Two independent $L$. esculentum quantitative trait loci (QTL) associated with improved color were identified based on linkage to markers mapping to chromosome 4 and chromosome 11. Epistatic interactions were identified between the two $L$. esculentum loci. Unexpected epistatic interactions also were identified between $L$. esculentum loci and an LA407 introgression on chromosome 7 present within IBL 2349. The two L. esculentum QTL and the epistatic interactions were confirmed in replicated trials with $F_{3}$ and $F_{4}$ families. The loci identified in this study and their epistatic interactions may provide additional tools for the improvement of red-fruited tomatoes in breeding programs.
\end{abstract}

Tomato (Lycopersicon esculentum Mill.) fruit color is one of the most important and complex attributes of fruit quality (Francis et al., 1995; Lee and Robinson, 1980). The complexity of tomato color is due to the presence of a diverse carotenoid pigment system with appearance conditioned by pigment types and concentrations, and subject to both genetic and environmental regulation (Koskitalo and Ormrod, 1972; Thompson et al., 1967). Many classically defined genes influencing tomato color have been identified and include apricot $(a t)$, beta-carotene $(B)$ and its allele old gold crimson $(o g c)$, delta $(D e l)$, diospyros $(d p s)$, ghost $(g h)$, green flesh $(g f)$, green ripe $(G r)$, high pigment-1 ( $h p-1)$, high pigment-2 $(h p-2)$ and its allele dark green $(d g)$, intense pigment $(I p)$, modifier $_{\text {beta-carotene }}\left(M o_{\mathrm{B}}\right)$, red color in yellow fruit $(r y)$, sherry $(s h)$, tangerine $(t)$, and yellow flesh $(r)$ (Jenkins and Mackinney, 1953, 1955; Kerr, 1958; Khudairi, 1972; Levin et al., 2003; Rick and Chetelet, 1993; Thompson et al., 1967; Tomes et al, 1953, 1956; VanTuinen et al., 1997; Young, 1956).

Clinical nutrition studies suggest a positive correlation between increased dietary consumption of red tomato products and reduced risk for certain types of cancers (Gartner et al., 1997; Stahl and Sies, 1996). Red tomatoes have most of their carotenoids in the form of lycopene (Gross, 1991), and interest in red color and lycopene content has re-emerged due to these findings. Tomatoes that carry the high pigment gene, $h p-2$, have increased total carotenoid levels and appear deeper red in color due to an increase in chromoplasts (e.g., Yen et al., 1997). The widely used old gold crimson $(o g c)$ gene increases the level of lycopene at the expense of beta-carotene due to the lack of lycopene cyclase activity (Ronen et al., 2000). While classically defined genesimprove the redness

\footnotetext{
Received for publication 27 Mar. 2003. Accepted for publication 27 Oct. 2003. Salaries and research support were provided by state and federal funds appropriated to The Ohio State University, Ohio Agricultural Research and Development Center, and grant funds from the Mid-American Food Processors. The mention of firm names or trade products does not imply that they are endorsed or recommended by The Ohio State University over other firms or similar products not mentioned. We thank Dr. Tea Meulia and the Molecular and Cellular Imaging Center, OARDC, Wooster, $\mathrm{OH}$ for assistance with DNA sequencing.

'To whom reprint requests should be addressed; e-mail francis77@osu.edu.
}

of tomatoes, a recent study by Sacks and Francis (2001) indicated that $\operatorname{gg}^{c}$ accounted for less than one-third of the variation seen in fruit color when evaluated among red-fruited breeding lines, openpollinated cultivars and hybrids. Potentially useful genetic variation for color was observed that was not explained by $\lg ^{c}$. These studies suggested that additional loci from L. esculentum could contribute to color. Quantitative trait loci influencing tomato color have been hypothesized based on studies involving interspecific crosses between the domesticated tomato and its wild relatives including five loci from L. pimpinellifolium LA1589 (Chen et al., 1999; Tanksley and Nelson, 1996), ten from L. peruvianum LA1706 (Fulton et al., 1997), fifteen from L. hirsutum LA1777 (Bernacchi et al., 1998), and nine from L. parviflorum LA2133 (Fulton et al., 2000). While several of these loci map to positions of classically defined genes, others appeared unique.

In this study, we evaluated an IBC population derived from crossing a wild, small green-fruited Lycopersicon species, L. hirsutum accession LA407, with L. esculentum (designated the LA407 IBC population) as a potential resource for the improvement of red-fruited tomato color. By using replicated field trials and the tomato fruit sampling strategy of Sacks and Francis (2001), significant differences in tomato color were identified between lines of the LA407 IBC population and between hybrids derived from each line crossed to a L. esculentum tester. Populations were then developed from the best inbred backcross line of this population (designated IBL 2349) to identify, map, and confirm the location of QTL contributing to the improved red color of this line. We identified L. esculentum loci and an L. hirsutum locus that interact to produce superior color in IBL 2349. The most significant effects were due to L. esculentum loci and their interaction.

\section{Materials and Methods}

Plant material. The LA407 IBC population has been previously described (Kabelka et al., 2002). Briefly, the population was derived from a cross between L. hirsutum, accession LA407, and two L. esculentum parents and consists of $64 \mathrm{BC}_{2} \mathrm{~S}_{5}$ lines (IBLs). 
The recurrent L.esculentum parents were 'Hunt 100' $\left(\mathrm{F}_{1}\right.$ and $\left.\mathrm{BC}_{1}\right)$ and 'Peto 95-43' $\left(\mathrm{BC}_{2}\right)$. Individual IBLs were developed through five generations of selfing with single seed descent. Selection for red fruit color (i.e., against $r$ and Beta) and determinate habit (against $\mathrm{sp}+$ ) was performed during population development. Hybrids were developed in the greenhouse from crossing each IBL with an open-pollinated L. esculentum variety Ohio 8245 (Berry and Gould, 1991). The IBLs within the LA407 IBC population and Ohio 8245 lack major beneficial genes and alleles $(h p-1, h p-2$, $d g$, and $o g^{c}$ ) traditionally used to improve the red color of tomato. The hybrid from the cross between IBL 2349 and Ohio 8245 was selfed to produce an $\mathrm{F}_{2}$ population. $\mathrm{F}_{3}$ and $\mathrm{F}_{4}$ progeny used to confirm significant color enhancing QTL within IBL 2349 were harvested from selfed $\mathrm{F}_{2}$ and $\mathrm{F}_{3}$ individuals, respectively.

FiELd TRIALS. The LA407 IBC population, the hybrids of each IBL, and five open-pollinated cultivars, T5020 ( ogc $/$ og and $h p-1 / h p-1$; Wann, 1997), Ohio 9241 (ogc/ogc), Ohio 86120 $\left(\operatorname{og}^{c} / \operatorname{og}^{c}\right)$, Ohio 7983 (Berry et al., 1992) and the hybrid Heinz $9423($ ogc $/ \circ c)$, used as checks, were evaluated in field trials at two locations and two blocks per location using a randomized complete block design in 1998. Field locations were The Ohio State University, Ohio Agricultural Research and Development Center(OARDC), Vegetable Crops Station in Fremont, Ohio, and The Ohio State University, Department of Horticulture and Crop Science Research Farm in Wooster, Ohio. Each plot consisted of eight to ten plants per genotype spaced $30 \mathrm{~cm}$ apart.

The IBL $2349 \times$ Ohio $8245 \mathrm{~F}_{2}$ population, composed of 160 individuals, was evaluated in Wooster, Ohio in 1999. Replicated parental controls were included. Seed were saved from 28 selected $\mathrm{F}_{2}$ plants representing both extremes such that individuals deviating from the $\mathrm{F}_{2}$ population mean by one standard deviation were advanced. The $28 \mathrm{~F}_{3}$ families were advanced in the greenhouse so that both $\mathrm{F}_{3}$ and $\mathrm{F}_{4}$ families could be evaluated in the same field trial. Plots consisting of $\mathrm{F}_{3}$ and $\mathrm{F}_{4}$ families were tested using a randomized complete block design at Fremont and at Wooster in 2000. Tests included two blocks per location of eight plants per family per plot and included replicated parental controls. Production practices for all field trials were conducted as recommended for commercial growers (Precheur, 2000).

TOMATO SAMPLING AND COLOR MEASUREMENTS. A pilot study of the LA407 IBC population was used to determine the range of hue, L and chroma (data not shown). Based on this pilot study and the strategy of Sacks and Francis (2001), 24 fruit per genotype were randomly harvested from each of four blocks (two locations, two blocks per location). For the range of values observed in the IBC population, this sampling strategy provided $95 \%$ confidence that differences could be detected between genotypes that deviated from the population mean by one standard deviation for $\mathrm{L}$ and chroma. This same strategy provided $90 \%$ confidence that differences could be detected between genotypes that deviated from the population mean by one standard deviation for hue.

To standardize maturity of tomatoes in all studies, randomly selected ripe fruit were harvested when individual pots had reached $80 \%$ ripeness. The pericarp of each fruit was exposed by cutting the stem end transversely with a sharp knife. Two objective color measurements were recorded approximately 180 degrees apart on the exposed pericarp of each fruit using a chromameter (CR-300; Minolta Camera Co., Ltd., Ramsey, N.J.).

Numeric descriptions of the red, green, yellow and blue components of tomato color were obtained using the " $\mathrm{L} * \mathrm{a} * \mathrm{~b} *$ " CIELAB color space (Commission Internationale de l'Eclairage, 1978). The $\mathrm{L}^{*}$ coordinate indicates darkness or lightness of color and ranges from black (0) to white (100). Coordinates, $\mathrm{a}^{*}$ and $\mathrm{b}^{*}$, indicate color directions: $+\mathrm{a}^{*}$ is the red direction, $-\mathrm{a}^{*}$ is the green direction, $+b^{*}$ is the yellow direction and $-b^{*}$ is the blue direction. Chroma (saturation or vividness of color) and hue (the basic tint of color) are derived from $\mathrm{a}^{*}$ and $\mathrm{b}^{*}$. Chroma is calculated as $\left(a^{* 2}+b^{* 2}\right)^{1 / 2}$. As chromaticity increases, a color becomes more intense; as it decreases a color becomes more dull. Hue is an angular measurement, calculated as $(180 / \pi)\left[\cos ^{-1}(\mathrm{a} / \mathrm{chroma})\right]$ for positive values of $b^{*}$, and is defined as starting at the red + $a^{*}$ axis at $0^{\circ}$. A hue angle of 45 degrees would be orange-red in color, whereas $90^{\circ}$ would be yellow.

Molecular Marker anAlysis. The LA407 IBC population had been previously characterized with 58 restriction fragment length polymorphism (RFLP) and five polymerase chain reaction (PCR)-based markers of known chromosome location providing coverage with at least two markers per chromosome arm (Kabelka et al., 2002). Procedures for DNA isolation, RFLP, and PCR, and all markers used for the analysis of the LA407 IBC population have been previously described (Kabelka et al., 2002). Tomato genomic clones CT114, TG199, and TG216(Tanksley et al., 1992) were used to monitor a L. hirsutum introgression on chromosome 7 in the IBL $2349 \times$ Ohio $8245 \mathrm{~F}_{2}$ population.

One hundred simple sequence repeat markers (SSR, http:// www.sgn.cornell.edu), 44 single nucleotide polymorphism (SNP, Yang, et al., 2003), and 250 random amplified polymorphic DNA (RAPD) primers (Biotechnology Laboratory, UBC, Vancouver, BC, Canada and Operon Technologies, Inc., Alameda, CA) were analyzed for use in characterizing the IBL $2349 \times$ Ohio $8245 \mathrm{~F}_{2}$ population using a modified bulk segregant approach (Michelmore et al., 1991). Polymorphisms were detected by amplification of template DNA from IBL 2349, Ohio 8245 and a pooled DNA sample consisting of IBLs 2305, 2315, 2338, 2359, 2365 and 2368 from the LA407 IBC population. The pooled DNA sample allowed exclusion of markers linked to an introgressed L. hirsutum LA407 region of chromosome 7 present within IBL 2349. Primers that were polymorphic in the screen were then used to amplify DNA from L. hirsutum LA407, L. esculentum Hunt 100, and Peto 95-43 before genotyping the IBL $2349 \times$ Ohio $8245 \mathrm{~F}_{2}$ population. Procedures for DNA isolation and PCR reactions for RAPD, SSR, and SNP amplifications have been previously described (Kabelka, 2001; Yang et al., 2003). The amplification products were separated on either $2 \%$ or $4 \%$ agarose gels (Amresco Biotechnology Grade 3:1 agarose, Solon, Ohio), stained with ethidium bromide, and photographed.

Cloning AND Sequencing of RAPD Products. Single-band RAPD products were cloned into the $\mathrm{pCR} 2.1$ vector (Invitrogen, Carlsbad, CA) following gel excision and purification. Plasmid DNA was purified, and cloned inserts were sequenced using 3'-dye dideoxynucleotide triphosphates labeling and an ABI PRISM 377. Extended PCR primers were designed based on sequence data as follows: UBC-192F, 5'-gcaagtcactctaggttcct-3'; UCB-192R, 5' -gcaagtcactattgactggac-3'; OPBB-09F, 5' -aggccggtcattagcttaatttg-3'; OPBB-09R, 5' -aggccggtcacgggttctatattg-3'. Amplification of UCB-192F/R was performed at $56 \mathrm{C}$ and amplification of OPBB-09F/R was performed at 60C.

MAP LOCATION OF POLYMORPHIC LOCI. Two populations were used to map and confirm the positions of the polymorphic markers used to genotype the IBL $2349 \times$ Ohio $8245 \mathrm{~F}_{2}$ population. The first population was a set of L. pennellii LA716 introgression lines (ILs, Eshed and Zamir, 1995). Each line is homozygous for a single chromosome segment derived from LA716 and delineated by RFLP markers introgressed from L. pennellii into L. escul- 
entum cultivar M82, such that the entire wild species genome is represented in a group of 50 lines. The second population was an $\mathrm{F}_{2}$ population consisting of 46 individuals derived from a cross of L. pimpinellifolium LA1589 and L. esculentum Sun1642 (van der Knaap and Tanksley, 2001). The SNP markers had been combined with RFLP markers to construct a linkage map of this population using the Kosambi mapping function of Mapmaker (Lander et al., 1987). The map position for each marker was determined from amplified products that were polymorphic between $L$. pennellii LA716, L. pimpinellifolium LA1589, and L. esculentum M82 and Sun1642 and had equivalent polymorphisms to those produced between L. hirsutum LA407, IBL 2349, L. esculentum Hunt 100, Peto 95-43, and Ohio 8245. Confirmation of the map position for the polymorphism detected by RAPD marker OPBB-09 also was based on linkage to the $j$ locus for jointed pedicel $\left(\chi^{2}=4.82, p<\right.$ 0.05) (Wing et al., 1994).

STATISTICAL ANALYSIS. Statistical analyses were performed using the GLM and MIXED procedures of SAS (Statistical Analysis System version 7.0, SAS Institute, Cary, N.C.). The statistical models and the rationale for these models have been described in detail previously (Kabelka et al., 2002; Sacks and Francis, 2001). General linear model analyses were used for phenotypic evaluation of hue, L, and chroma within the LA407 IBC population across environments. Genotypes were considered as fixed effects whereas location and blocks were considered as random effects. Fisher's LSD was used for pair-wise comparisons of means. Pearson (r) correlations of phenotypic means between hue, L, and chroma were calculated using the CORR procedure of SAS. Estimates of gene numbers influencing hue, L, and chroma were obtained using the approach of Eskridge and Coyne (Eskridge and Coyne, 1996). Broad-sense heritability estimates for hue, L, and chroma were calculated based on partitioning variation and obtaining mean square estimates across environments.

Phenotypic analyses of the $\mathrm{F}_{2}, \mathrm{~F}_{3}$, and $\mathrm{F}_{4}$ populations derived from IBL $2349 \times$ Ohio 8245 were conducted using general linear and mixed model analyses of variance. Within the mixed model analyses of the $\mathrm{F}_{3}$ and $\mathrm{F}_{4}$ progeny, genotype was considered as a fixed effect whereas location and blocks were considered as random effects. Realized heritability estimates based on phenotypic selection of hue, L, and chroma were calculated according to $h^{2}=$ $\left(X_{\text {highF4 }}-X_{\text {lowF } 4}\right) /\left(X_{\text {highF2 }}-X_{\text {lowF2 }}\right)($ Fehr, 1993). Linkage relationships between genotypic classes of each molecular marker with hue, $\mathrm{L}$, and chroma within the IBL $2349 \times$ Ohio $8245 \mathrm{~F}_{2}, \mathrm{~F}_{3}$, and $\mathrm{F}_{4}$ populations were determined using single marker-trait analysis using a general linear model. Linkage relationships of the $\mathrm{F}_{3}$ and $\mathrm{F}_{4}$ progeny were determined within and across environments with markers considered as fixed effects and location, blocks, and genotype considered as random effects. Significant $(p<0.05)$ differences in marker class means were interpreted as linkage of a marker locus to hue, L, or chroma. Total phenotypic variation explained by markers identified for hue, $\mathrm{L}$, and chroma in the $\mathrm{F}_{2}$ population was estimated by the $R^{2}$ value and for the $\mathrm{F}_{3}$ and $\mathrm{F}_{4}$ populations calculated by estimating variance components by restricted maximum likelihood (REML). Linkage relationships between marker loci were determined by pair-wise chi-square analysis.

Digenic epistasis was tested using a two-factor analysis of variance where the model contained main effects for each marker, an effect for the interaction between alleles of the two markers, and the error term containing both residual genetic effects and experimental error ( $\mathrm{Li}, 1997)$. A significant interaction effect in the analysis was interpreted as evidence for epistasis between QTL linked to the two markers. In order to preclude the detection of false positive interactions arising from background genetic effects in the $\mathrm{F}_{2}$ population, significant interactions were considered putative until confirmed in subsequent generations where phenotypic evaluation was conducted in replicated trials.

\section{Results}

Phenotypic evaluation of tomato color in the LA407 IBC POPULATION. In this study improved tomato color is based on previous observations of Sacks and Francis (2001) and is defined as a reduction in values of hue (tint of color) and $\mathrm{L}$ (darkness of color) and an increase in chroma (saturation or vividness of color). Mean comparisons for hue. L, and chroma of a subset of IBL from the LA407 IBC population, hybrids, and checks are provided in Table 1. The subset of IBL and hybrids presented in Table 1 are those with values of hue, L, and chroma similar or superior to the checks evaluated in this study. The range of mean values for hue, L, and chroma (Table 1) across two environments was at least three fold higher than we have reported for breeding populations consisting of only elite germplasm (Sacks and Francis, 2001). The increased phenotypic variation suggests greater genotypic variation. However, the population mean for all color traits was lower than the mean of breeding populations (Table 1, and Sacks and Francis, 2001). These observations suggest that the increase in genetic variation in the LA407 IBC population is due to the introduction of alleles that shift the population toward undesirable color.

The position of individual IBLs and controls suggests that genes for improved color may exist within the LA407 IBC population

Table 1. Mean comparison for hue, $\mathrm{L}$ and chroma of a subset of inbred backcross lines from the LA407 IBC population, hybrids, and checks across two environments in Ohio (1998).

\begin{tabular}{llll}
\hline Genotype $^{\mathrm{z}}$ & \multicolumn{1}{c}{ Hue $^{\mathrm{y}}$} & \multicolumn{1}{c}{$\mathrm{L}$} & \multicolumn{1}{c}{ Chroma } \\
\hline OP T5020 $\left(o g^{c}, h p-1\right)$ & $33.7 \mathrm{a}$ & $35.2 \mathrm{a}$ & $38.1 \mathrm{~d}, \mathrm{e}, \mathrm{f}, \mathrm{g}, \mathrm{h}$ \\
IBL 2349 & $38.7 \mathrm{~b}, \mathrm{c}$ & $39.5 \mathrm{~b}, \mathrm{c}, \mathrm{d}$ & $36.6 \mathrm{~b}, \mathrm{c}, \mathrm{d}, \mathrm{e}$ \\
OP Ohio 9241 $(o g c)$ & $41.5 \mathrm{~b}, \mathrm{c}, \mathrm{d}, \mathrm{e}$ & $41.6 \mathrm{c}, \mathrm{d}, \mathrm{e}, \mathrm{f}$ & $39.4 \mathrm{f}, \mathrm{g}, \mathrm{h}$ \\
IBL 2339 & $41.6 \mathrm{~b}, \mathrm{c}, \mathrm{d}, \mathrm{e}$ & $42.7 \mathrm{c}, \mathrm{d}, \mathrm{e}, \mathrm{f}, \mathrm{g}$ & $41.3 \mathrm{i}$ \\
IBL 2306 & $41.8 \mathrm{~b}, \mathrm{c}, \mathrm{d}, \mathrm{e}$ & $43.1 \mathrm{~d}, \mathrm{e}, \mathrm{f}, \mathrm{g}$ & $36.9 \mathrm{~b}, \mathrm{c}, \mathrm{d}, \mathrm{e}, \mathrm{f}$ \\
OP Ohio 86120 $(o g c)$ & $42.5 \mathrm{~b}, \mathrm{c}, \mathrm{d}, \mathrm{e}$ & $40.9 \mathrm{~b}, \mathrm{c}, \mathrm{d}, \mathrm{e}$ & $37.0 \mathrm{~b}, \mathrm{c}, \mathrm{d}, \mathrm{e}, \mathrm{f}$ \\
Heinz 9423 $\left(\mathrm{og}^{c}\right)$ & $42.5 \mathrm{~b}, \mathrm{c}, \mathrm{d}, \mathrm{e}$ & $44.0 \mathrm{e}, \mathrm{f}, \mathrm{g}$ & $41.1 \mathrm{i}$ \\
IBL 2350 & $43.8 \mathrm{c}, \mathrm{d}, \mathrm{e}$ & $42.3 \mathrm{c}, \mathrm{d}, \mathrm{e}, \mathrm{f}, \mathrm{g}$ & $33.8 \mathrm{a}$ \\
F1 2306 & $43.9 \mathrm{c}, \mathrm{d}, \mathrm{e}$ & $43.3 \mathrm{~d}, \mathrm{e}, \mathrm{f}, \mathrm{g}$ & $37.7 \mathrm{c}, \mathrm{d}, \mathrm{e}, \mathrm{f}, \mathrm{g}$ \\
F1 2348 & $44.0 \mathrm{c}, \mathrm{d}, \mathrm{e}$ & $43.3 \mathrm{~d}, \mathrm{e}, \mathrm{f}, \mathrm{g}$ & $38.8 \mathrm{e}, \mathrm{f}, \mathrm{g}, \mathrm{h}$ \\
IBL 2348 & $45.0 \mathrm{c}, \mathrm{d}, \mathrm{e}, \mathrm{f}$ & $43.3 \mathrm{~d}, \mathrm{e}, \mathrm{f}, \mathrm{g}$ & $36.8 \mathrm{~b}, \mathrm{c}, \mathrm{d}, \mathrm{e}, \mathrm{f}$ \\
OP Ohio 8245 & $48.9 \mathrm{e}, \mathrm{f}, \mathrm{g}$ & $46.0 \mathrm{~h}$ & $38.0 \mathrm{~d}, \mathrm{e}, \mathrm{f}, \mathrm{g}$ \\
OP Ohio 7983 & $49.5 \mathrm{f}, \mathrm{g}$ & $43.9 \mathrm{e}, \mathrm{f}, \mathrm{g}$ & $34.6 \mathrm{a}$ \\
F1 2349 & $51.1 \mathrm{f}, \mathrm{g}$ & $46.7 \mathrm{~h}$ & $36.1 \mathrm{~b}, \mathrm{c}, \mathrm{d}$ \\
F1 2339 & $51.4 \mathrm{f,g}$ & $47.0 \mathrm{~h}$ & $38.0 \mathrm{~d}, \mathrm{e}, \mathrm{f}, \mathrm{g}$ \\
F1 2350 & $52.5 \mathrm{f}, \mathrm{g}$ & $47.3 \mathrm{~h}$ & $36.0 \mathrm{~b}, \mathrm{c}, \mathrm{d}$ \\
Range & $33.7-75.1$ & $35.2-56.5$ & $24.0-45.8$ \\
Mean & 51.9 & 46.6 & 35.6 \\
LSD $_{(0.05)}$ & 3.9 & 1.9 & 1.3 \\
\hline
\end{tabular}

${ }^{z}$ Genotypes represent several red-fruited open-pollinated (OP) varieties, the hybrid Heinz 9423, a subset of inbred backcross lines (IBL) of the LA407 inbred backcross population, and hybrids (F1) derived from crossing each IBL with Ohio 8245.

yColor measurements of hue (tint of color), L (darkness of color), and chroma (saturation or vividness of color) were obtained using the CIELAB color space. Means followed by the same letter are not significantly different at $p=0.05$. 
Table 2. Marker loci significantly $(p<0.05)$ associated with tomato color, based on hue, $\mathrm{L}$ and chroma, within and across two environments in Ohio.

\begin{tabular}{|c|c|c|c|c|c|c|c|c|c|c|}
\hline \multirow[b]{2}{*}{ Colort $^{t}$} & \multirow[b]{2}{*}{ Location } & \multirow[b]{2}{*}{ Genotype $^{u}$} & \multirow[b]{2}{*}{ Chromav $^{\text {. }}$} & \multirow[b]{2}{*}{ Markerw } & \multicolumn{3}{|c|}{$\begin{array}{l}\text { Genotypic means of } \\
\text { marker classes }\end{array}$} & \multirow{2}{*}{$\begin{array}{l}\text { Effect of } \\
\mathrm{H} \text { alleley }\end{array}$} & \multirow[b]{2}{*}{$p$} & \multirow[b]{2}{*}{$\mathrm{Vp}^{\mathrm{z}}$} \\
\hline & & & & & $\mathrm{HH}$ & $\mathrm{HE}$ & $\mathrm{EE}$ & & & \\
\hline \multirow[t]{3}{*}{ Hue } & Fremont & F1 & $10 \mathrm{~S}$ & TG230 & & 67.89 & 56.19 & - & 0.0057 & 0.87 \\
\hline & Wooster & IBC & $3 \mathrm{~S}$ & TG479 & 39.98 & & 48.74 & + & 0.0356 & 0.36 \\
\hline & Across environments & $\mathrm{F} 1$ & $6 \mathrm{~L}$ & TG482 & & 45.23 & 51.53 & + & 0.0329 & 0.17 \\
\hline \multirow[t]{10}{*}{$\mathrm{L}$} & Fremont & $\mathrm{F} 1$ & $6 \mathrm{~L}$ & TG482 & & 44.54 & 49.06 & + & 0.0256 & 0.70 \\
\hline & & $\mathrm{F} 1$ & $12 \mathrm{~L}$ & TG394 & & 46.75 & 49.15 & + & 0.0482 & 0.18 \\
\hline & Wooster & $\mathrm{F} 1$ & $1 \mathrm{~S}$ & TG301 & & 40.51 & 44.05 & + & 0.0131 & 0.72 \\
\hline & & $\mathrm{F} 1$ & $2 \mathrm{~S}$ & TG616 & & 41.52 & 44.04 & + & 0.0446 & 0.32 \\
\hline & & $\mathrm{F} 1$ & $6 \mathrm{~S}$ & $\operatorname{Rex} 13$ & & 48.93 & 43.80 & - & 0.0357 & 0.89 \\
\hline & & $\mathrm{F} 1$ & $6 \mathrm{~L}$ & TG482 & & 40.49 & 43.99 & + & 0.0451 & 0.61 \\
\hline & & IBC & $11 \mathrm{~S}$ & TG523 & 39.81 & & 44.59 & + & 0.0242 & 0.39 \\
\hline & Across environments & $\mathrm{F} 1$ & $1 \mathrm{~S}$ & TG301 & & 43.17 & 46.56 & + & 0.0098 & 0.22 \\
\hline & & $\mathrm{F} 1$ & $6 \mathrm{~L}$ & TG482 & & 42.51 & 46.53 & + & 0.0121 & 0.32 \\
\hline & & IBC & $11 \mathrm{~S}$ & TG523 & 43.28 & & 47.25 & + & 0.0411 & 0.15 \\
\hline \multirow[t]{14}{*}{ Chroma } & Fremont & IBC & $2 \mathrm{~L}$ & TG492 & 30.79 & & 35.51 & - & 0.0073 & 0.48 \\
\hline & & IBC & $3 \mathrm{~S}$ & TG525 & 31.23 & & 35.56 & - & 0.0047 & 0.53 \\
\hline & & $\mathrm{F} 1$ & $5 \mathrm{~L}$ & TG524 & & 30.36 & 35.90 & - & 0.0093 & 0.86 \\
\hline & & $\mathrm{F} 1$ & $8 \mathrm{~S}$ & TG309 & & 33.29 & 35.93 & - & 0.0360 & 0.56 \\
\hline & & $\mathrm{F} 1$ & $10 \mathrm{~L}$ & TG420 & & 34.11 & 36.02 & - & 0.0254 & 0.28 \\
\hline & Wooster & $\mathrm{F} 1$ & $2 \mathrm{~L}$ & TG091 & & 34.11 & 36.21 & - & 0.0216 & 0.32 \\
\hline & & $\mathrm{F} 1$ & $2 \mathrm{~L}$ & TG492 & & 32.58 & 36.18 & - & 0.0038 & 0.89 \\
\hline & & F1 & $8 \mathrm{~S}$ & TG309 & & 33.22 & 36.15 & - & 0.0201 & 0.61 \\
\hline & & $\mathrm{F} 1$ & $9 \mathrm{~L}$ & TG421 & & 33.80 & 36.16 & - & 0.0325 & 0.38 \\
\hline & Across environments & $\mathrm{F} 1$ & $2 \mathrm{~L}$ & TG091 & & 34.42 & 36.07 & - & 0.0392 & 0.19 \\
\hline & & IBC & $2 \mathrm{~L}$ & TG492 & 30.94 & & 35.17 & - & 0.0158 & 0.40 \\
\hline & & $\mathrm{F} 1$ & $2 \mathrm{~L}$ & TG492 & & 33.25 & 36.04 & - & 0.0103 & 0.60 \\
\hline & & IBC & $2 \mathrm{~S}$ & TG525 & 31.33 & & 35.20 & - & 0.0188 & 0.35 \\
\hline & & $\mathrm{F} 1$ & $8 \mathrm{~S}$ & TG309 & & 33.25 & 36.04 & - & 0.0106 & 0.59 \\
\hline
\end{tabular}

tMeasurements of hue (tint), L (darkness), and chroma (saturation) were obtained using the CIELAB color space.

uIBC = LA407 IBC population; F1 = Hybrid between each IBL with Ohio 8245.

${ } \mathrm{L}=$ long arm of chromosome; $\mathrm{S}=$ short arm of chromosome.

wRGA, Rex13, and TG091 are PCR-based markers while the remainder are RFLP markers.

${ }^{\times} \mathrm{HH}=$ homozygous L. hirsutum LA407; HE = heterozygote; $\mathrm{EE}=$ homozygous L. esculentum.

yEffect of L. hirsutum LA407 (H) allele on hue, L, and chroma.

${ }^{2}$ Proportion of total phenotypic variation explained by marker locus.

despite the contribution of negative alleles from the L. hirsutum donor. The high lycopene line T5020, which is homozygous for $o g^{c}$ and $h p-1$, was significantly different from all other genotypes for hue and L. This is consistent with previous studies that indicate $o g c$ and $h p-1$ have a large positive effect on tomato color (Sacks and Francis, 2001; Thompson et al., 1965). The effect of either ogc or $h p-1$ on chroma, however, was not apparent since T5020 did not exhibit the highest chroma. Several IBLs exhibited low hue and $\mathrm{L}$ values in the same range as Ohio 9241, Ohio 86120, and the hybrid Heinz 9423 all of which are homozygous for $o g^{c}$. This observation is significant as the LA407 IBC population lacks characterized major genes such as $o g^{c}$ and $h p-1$ that contribute to color and useful or unique genes for improved color may therefore exist within adapted and wild germplasm as suggested by previous studies (Bernacchi et al., 1998; Fulton et al., 1997, 2000; Sacks and Francis, 2001; Tanksley et al., 1996). Despite the identification of positive variation for color, it is clear that most of the increase in genetic variation is due to alleles that have negative effects on color.

Phenotypic variation among genotypes across environments for hue, L, and chroma were significant $(p<0.0001)$. Environmental differences were significant for hue $(p=0.0045)$ and $\mathrm{L}$ $(p=0.0137)$ while genotype $\times$ environment interactions were significant for hue $(p=0.0058), \mathrm{L}(p=0.0001)$, and chroma ( $p=$ 0.0001 ). The significant environment and genotype $\times$ environment interactions may be due to a high incidence of the physiological color disorder, yellow shoulder disorder (YSD), prevalent at the OARDC farm in Fremont, Ohio (Francis et al., 2000). A significant positive linear correlation was observed between hue and $\mathrm{L}$ values $(r=0.895, p<0.0001)$ but not between hue and chroma $(r=0.075, p=0.0872)$ or L and chroma $(r=0.0675, p=$ $0.165)$. The poor correlation with chroma may suggests that different genes are involved in the saturation or vividness of tomato color compared to the absolute color of tomato as measured by hue and L. Estimates of the number of genes in the LA407 IBC population influencing tomato color within and among the two Ohio environments ranged from 2 to 4 . Broad-sense heritability estimates across environments for hue, $\mathrm{L}$ and chroma were 0.78 , 0.74 and 0.79 , respectively.

QTL ANALYSIS OF TOMATO COLOR IN THE LA407 IBC POPULATION. For all color traits, 13 putative QTL explaining 15-89\% of the total phenotypic variation for color were identified within and across the two environments (Table 2). Of these, six chromosomal regions increased the redness of tomato fruit by decreasing hue 
and L values or increasing chroma. Only two positive QTL, on $3 \mathrm{~S}$ and $11 \mathrm{~S}$, were detected in IBC lines homozygous for the $L$. hirsutum LA407 allele. Only one positive QTL, affecting the L value in hybrids and located on 6L, was detected in each location and across environments. QTL on chromosomes 2L and 8S had a negative effect on chroma that was detected in each location and across locations. None of the individual IBLs with color equal to that of commercial checks possessed any of the six positive QTL from L. hirsutum LA407 suggesting that L. esculentum alleles, undetected $L$. hirustum alleles, or epistatic interactions may have a more significant effect on color.

GENETIC ANALYSIS OF IBL 2349. To investigate the genetic basis of improved color, we developed populations based on IBL 2349 due to its superior color (Table 1). Frequency distributions of the $\mathrm{F}_{2}$ population for hue, $\mathrm{L}$, and chroma were continuous (data not shown). IBL 2349 was homozygous for an introgressed $L$. hirsutum LA407 region on chromosome 7. The chromosome 7 introgression was not associated with tomato fruit color (hue, L, or chroma) based on single-marker analysis of the IBL 2349 x Ohio $8245 \mathrm{~F}_{2}$ population with three RFLP markers (CT114, TG199, and TG216) spanning the introgression. Observed segregation approximated the expected 1:2:1 $(p>0.05)$ ratio for codominant markers.

A modified bulk segregant approach allowed the identification three RAPD primers, three SSR markers, and five SNP markers (Table 3) that exhibited banding patterns distinguishing IBL 2349 from Ohio 8245 while excluding the L. hirsutum introgression on chromosome 7. Attempts to convert the RAPD polymorphisms into more robust PCR-based or RFLP markers failed due to the lack of sequence divergence between either parent, due to high copy DNA within the clones based on Southern analysis (data not shown), and because the extended primers failed to amplify polymorphic bands (presumably because the original polymorphism affected decamer binding). DNA of the $\mathrm{F}_{2}$ population was genotyped with all 11 markers and observed segregation approximated the expected 3:1 $(p>0.05)$ ratio for dominant RAPD markers and 1:2:1 segregation for codominant SSR and SNP markers ( $p$ $>0.05$ ). Examination of polymorphisms in pair-wise combination detected linkage between RAPD marker UBC-192 and SNP marker LEMT3 on chromosome $4\left(\chi^{2}=112.01, p<0.001\right)$ The polymorphism detected by RAPD marker OPBB-09 also was linked to jointed pedicel $\left(\chi^{2}=4.82, p<0.05\right)$, thus confirming its map position on chromosome 11. All other markers revealed independent assortment.

QTL ASSOCIATED WITH THE IMPROVEMENT OF TOMATO COLOR IN IBL 2349. Single marker-trait analysis of the $F_{2}$ population revealed that the polymorphisms detected by UBC-192, LEMT3, and OPBB-09 were significantly associated with hue, L, and chroma (Table 4). $\mathrm{F}_{2}$ plants with the Ohio 8245 allele marked by UBC-192 and LEMT3 showed an increase in chroma values. UBC-192 explained $17 \%$ of the total phenotypic variation for chroma while the linked codominant marker, LEMT3, explained $22 \%$ of the variation for chroma. UBC-192 also explained 3\% of the total phenotypic variation for hue. $\mathrm{F}_{2}$ plants with the Hunt 100 allele of OPBB-09 showed decreasing hue and L values and explained $13 \%$ of the total phenotypic variation for hue and $12 \%$ for $\mathrm{L}$. The other polymorphic markers were not found associated with hue, L, or chroma based on single marker-trait analysis. Thus two QTL identified by single marker-trait analysis, one on chromosome 4 and one on chromosome 11, were due to the positive effects of alleles from L. esculentum.

CONFIRMATION OF QTL ASSOCIATED WITH THE IMPROVEMENT OF TOMATO COLOR IN IBL 2349. $\mathrm{F}_{3}$ and $\mathrm{F}_{4}$ progeny originating from selected IBL $2349 \times$ Ohio $8245 \mathrm{~F}_{2}$ individuals that deviated from the $\mathrm{F}_{2}$ population mean by one standard deviation were evaluated for hue, L, and chroma in replicated field trials. Mixed model analysis of variance of the phenotypic data revealed location and location $\times$ genotypic differences were nonsignificant for hue ( $p=0.8546$ and 0.5029 , respectively) and $\mathrm{L}(p=0.3434$ and 0.4805 , respectively) but significant for chroma $(p<0.0001$ and $p<0.0001$, respectively). Realized heritability estimates for the improvement of tomato color based on phenotypic selection were 0.76 for hue, 0.55 for $\mathrm{L}$, and 0.48 for chroma.

Tests for an association between the codominant SNP marker LEMT3 and dominant RAPD marker OPBB-09 with hue, L, and chroma in $\mathrm{F}_{3}$ and $\mathrm{F}_{4}$ families were conducted. Location differences were nonsignificant with LEMT3 and OPBB-09 for hue $(p=0.9676$ and 0.8235 , respectively), $\mathrm{L}(p=0.3618$ and 0.3399 ,

Table 3. PCR-based markers used for genotypic analysis of IBL 2349 x Ohio 8245.

\begin{tabular}{|c|c|c|c|}
\hline$\overline{\text { Locus }^{2}}$ & Marker type & Chromosome & Primer \\
\hline$\overline{\mathrm{UBC}-192}$ & RAPD & 4 & F/R GCAAGTCACT \\
\hline OPBB-09 & RAPD & 11 & F/R AGGCCGGTCA \\
\hline OPG-16 & RAPD & Unknown & F/R AGCGTCCTCC \\
\hline LEOH8 & SNP & 9 & F: CCA CTG ATC AAT GTG GTG GA \\
\hline (Hae III) & & & R: CAA CCA CAA ATG GCT CCT AAA \\
\hline LEOH17 & SNP & Unknown & F: CAG ACG AGA AGC AAG TTG AGG \\
\hline$(\mathrm{BseN} \mathrm{I})$ & & & R: CTA CCA CTG CGT GCT TTG AC \\
\hline LEOH19 & SNP & 12 & F: AAG GCT CAG AAA GGG TCC AT \\
\hline (BsaB I) & & & R: TGA GTT CAT CAA CAC ATC ACA CA \\
\hline LEOH23 & SNP & 2 & F: CTA TGC GTT TGT CGG TCG T \\
\hline (Tsp509 I) & & & R: CAA GGT AGT TGA AGG TAT GAC CA \\
\hline LEMT3 & SNP & 4 & F: TTG ATA TAT TCC ATG TGT GTC TC \\
\hline$(\mathrm{NmuC} \mathrm{I})$ & & & R: AAC TAC AAA TTA ACA AAC TTA AAT GG \\
\hline \multirow[t]{2}{*}{ SSR96 } & SSR & 2 & F: GGGTTATCAATGATGCAATGG \\
\hline & & & R: CCTTTATGTCAGCCGGTGTT \\
\hline \multirow[t]{2}{*}{ SSR104 } & SSR & 2 & F: TTCCATTTGAATTCCAACCC \\
\hline & & & R: CCCACTGCACATCAACTGAC \\
\hline \multirow[t]{2}{*}{ SSR111 } & SSR & 3 & F: TTCTTCCСTTCCATCAGTTCT \\
\hline & & & R: TTTGCTGCTATACTGCTGACA \\
\hline
\end{tabular}

${ }^{2}$ Restiction enzymes used to detect polymorphisms following PCR amplification are indicated below the marker designation. 
respectively), and chroma ( $p=0.1796$ and 0.0671 , respectively). Marker $\times$ location interactions were significant for LEMT3 with $\mathrm{L}(p=0.0201)$ and chroma $(p=0.0001)$ but nonsignificant for hue $(p=0.7343)$. For OPBB-09, marker $\times$ location interactions for hue $(p=0.2383), \mathrm{L}(p=0.1874)$, and chroma $(p=0.3293)$ were nonsignificant. The association between markers LEMT3 and OPBB-09 with hue, L, and chroma were confirmed at each location and across locations (Table 4). Estimates of variance components revealed that LEMT3 was associated with $14 \%$ to $80 \%$ and OPBB-09 with $25 \%$ to $44 \%$ of the total phenotypic variation for hue, L, and chroma within and across environments.

EPISTASIS OF QTL. Epistatic interactions were tested between the QTL on chromosome 4 marked by LEMT3 and chromosome 11 marked by OPBB-09 along with three RFLP markers, CT114, TG199, and TG216, that tag the L. hirsutum LA407 introgressed region of chromosome 7 in IBL 2349. Two-factor analysis of variance for epistasis between the loci on chromosome 4 and chromosome 11 revealed highly significant interactions for hue, $\mathrm{L}$, and chroma (Table 5) in the $\mathrm{F}_{2}$ population. Though the L. hirsutum LA407 introgression on chromosome 7 within IBL 2349 was not significant in single marker-trait analysis, we unexpectedly detected significant epistatic interactions between the QTL on chromosome 4 and 11 with RFLP markers on chromosome 7. Mean separations of the extreme genotypic classes of the significant interactions were consistent with expectations for epistasis in all cases except between chromosome 11 and TG216 where extreme genotypic classes were nonsignificant. Confirmation for epistatic interactions was provided by $\mathrm{F}_{3}$ and $\mathrm{F}_{4}$ families that originated from selected $\mathrm{F}_{2}$ individuals (Tables 5 and 6).

\section{Discussion}

Several QTL mapping studies using interspecific crosses between the cultivated tomato and its wild relatives have been performed (e.g., Bernacchi et al., 1998; Chen et al., 1999; Fulton et al., 1997, 2000; Tanksley and Nelson, 1996; Tanksley et al., 1996). One study, in particular, evaluated color in an advanced backcross (AB)-QTL population derived from crossing L. hirsutum accession LA1777 with L. esculentum (Bernacchi et al., 1998). In comparing the putative QTL associated with tomato color in our LA407 IBC population with those of the LA1777 AB-QTL population, introgressed regions on chromosome $1 \mathrm{~S}$ and $2 \mathrm{~S}$ were positively associated with fruit color in both populations. Introgressed regions on chromosome 10L were negatively associated in both populations. An introgressed region on chromosome $9 \mathrm{~L}$ revealed opposite effects (negative in the LA407 IBC population and positive in the LA1777 AB-QTL population). Anegative QTL on chromosome 4, fc 4.1, from the LA1777 population may be an

Table 4. Linkage relationships between markers significantly associated $(\mathrm{P}<0.05)$ with hue (tint of color), $\mathrm{L}$ (darkness or lightness of color), and chroma (vividness of color) in $\mathrm{F}_{2}, \mathrm{~F}_{3}$ and $\mathrm{F}_{4}$ progeny derived by crossing IBL 2349 with Ohio 8245.

\begin{tabular}{|c|c|c|c|c|c|c|c|}
\hline \multirow[b]{2}{*}{ Markerz } & \multirow[b]{2}{*}{ Location } & \multicolumn{2}{|c|}{ Hue } & \multicolumn{2}{|c|}{$\mathrm{L}$} & \multicolumn{2}{|c|}{ Chroma } \\
\hline & & $P$ & Vpy & $P$ & $\mathrm{Vp}$ & $P$ & $\mathrm{Vp}$ \\
\hline \multicolumn{8}{|l|}{$\overline{\mathrm{F}_{2} \text { population }}$} \\
\hline UBC-192 (4) & Wooster & 0.0281 & 0.03 & NS & --- & 0.0001 & 0.17 \\
\hline LEMT3 (4) & Wooster & NS & --- & NS & --- & $<0.0001$ & 0.22 \\
\hline OPBB-09 (11) & Wooster & 0.0001 & 0.13 & 0.0001 & 0.12 & NS & --- \\
\hline \multicolumn{8}{|l|}{$\mathrm{F}_{3} / \mathrm{F}_{4}$ families } \\
\hline \multirow[t]{3}{*}{ LEMT3 (4) } & Wooster & 0.0386 & 0.18 & 0.0328 & 0.22 & 0.0001 & 0.65 \\
\hline & Fremont & NS & --- & 0.0028 & 0.41 & 0.0001 & 0.80 \\
\hline & Across environments & 0.0354 & 0.14 & NS & - & NS & --- \\
\hline \multirow[t]{3}{*}{ OPBB-09 (11) } & Wooster & 0.0097 & 0.25 & 0.0007 & 0.44 & NS & --- \\
\hline & Fremont & 0.0086 & 0.31 & 0.0016 & 0.42 & NS & --- \\
\hline & Across environments & 0.0261 & 0.27 & 0.0085 & 0.41 & NS & --- \\
\hline
\end{tabular}

¿UBC-192 and LEMT3 allele of Ohio 8245; OPBB-09 allele of Hunt 100.

$\mathrm{y} \mathrm{Vp}=$ proportion of total phenotypic variation explained by marker locus.

${ }^{x}$ Markers are indicated with their chromosomal location in parenthesis.

NsNonsignificant at $p<0.05$.

Table 5. Epistatic interactions between polymorphic markers evaluated in the IBL 2349 x Ohio 8245 derived $\mathrm{F}_{2}$ population and in subsequent $\mathrm{F}_{3}$ and $\mathrm{F}_{4}$ families for hue, $\mathrm{L}$, and chroma.

\begin{tabular}{|c|c|c|c|c|c|c|}
\hline \multirow[b]{2}{*}{ Marker ${ }^{\mathrm{z}}$} & \multirow[b]{2}{*}{ Chroma } & \multirow[b]{2}{*}{ Marker } & \multirow[b]{2}{*}{ Chroma } & \multicolumn{3}{|c|}{$P$} \\
\hline & & & & Hue & $\mathrm{L}$ & Chroma \\
\hline \multicolumn{7}{|l|}{$\mathrm{F}_{2}$ population } \\
\hline \multirow{4}{*}{ LEMT3 } & 4 & OPBB-09 & 11 & 0.0001 & 0.0002 & 0.0001 \\
\hline & & CT114 & 7 & 0.3769 & 0.7530 & 0.0001 \\
\hline & & TG199 & 7 & 0.0150 & 0.1108 & 0.0001 \\
\hline & & TG216 & 7 & 0.1407 & 0.7127 & 0.0001 \\
\hline \multirow[t]{3}{*}{ ОРВВ-09 } & 11 & CT114 & 7 & 0.0004 & 0.0004 & 0.4343 \\
\hline & & TG199 & 7 & 0.0007 & 0.0002 & 0.2962 \\
\hline & & TG216 & 7 & 0.0003 & 0.0001 & 0.1229 \\
\hline \multicolumn{7}{|c|}{$\mathrm{F}_{3} / \mathrm{F}_{4}$ families } \\
\hline \multirow[t]{2}{*}{ LEMT3 } & 4 & OPBB-09 & 11 & 0.0005 & 0.0001 & 0.0001 \\
\hline & & TG199 & 7 & 0.0350 & 0.0069 & 0.0001 \\
\hline OPBB-09 & 11 & TG199 & 7 & 0.0419 & 0.0001 & 0.0018 \\
\hline
\end{tabular}

${ }^{2}$ LEMT3 allele of Ohio 8245; OPBB-09 allele of Hunt 100; CT114, TG199, TG216 alleles of IBL 2349 (L. hirsutum LA407). 
Table 6. Mean comparison for hue, $\mathrm{L}$, and chroma across two environments for combinations of alleles found in $\mathrm{F}_{3}$ and $\mathrm{F}_{4}$ families derived from the IBL $2349 \times$ Ohio $8245 \mathrm{~F}_{2}$ population.

\begin{tabular}{|c|c|c|c|c|}
\hline \multirow[b]{2}{*}{ Marker $^{z}$} & \multirow[b]{2}{*}{ Hue } & \multicolumn{3}{|c|}{ Color trait } \\
\hline & & $\mathrm{L}$ & Chroma & \\
\hline OPBB9 (11) & LEMT3 (4) & & & \\
\hline Hunt100 & Hunt100 & 39.26 & 39.81 & 36.05 \\
\hline Hunt 100 & OH8245 & 43.38 & 42.23 & 38.82 \\
\hline OH8245 & OH8245 & 45.37 & 44.09 & 39.15 \\
\hline OH8245 & Hunt100 & 46.47 & 44.6 & 36.95 \\
\hline OPBB9 (11) & TG199 (7) & & & \\
\hline$\overline{\text { Hunt100 }}$ & LA407 & 41.45 & 40.50 & 37.04 \\
\hline Hunt 100 & Heterozygous & 41.81 & 41.43 & 38.84 \\
\hline Hunt 100 & OH8245 & 43.23 & 42.80 & 37.28 \\
\hline OH8245 & Heterozygous & 45.37 & 44.09 & 39.16 \\
\hline OH8245 & $\mathrm{OH} 8245$ & 46.47 & 44.60 & 36.95 \\
\hline OH8245 & LA407 & NTy & NT & NT \\
\hline LEMT3 (4) & TG199 (7) & & & \\
\hline Hunt100 & Heterozygous & 38.30 & 39.01 & 34.41 \\
\hline Hunt 100 & LA407 & 40.11 & 38.54 & 32.19 \\
\hline OH8245 & LA407 & 42.09 & 40.76 & 36.17 \\
\hline Hunt 100 & OH8245 & 42.69 & 40.87 & 32.41 \\
\hline OH8245 & Heterozygous & 44.38 & 42.94 & 37.43 \\
\hline OH8245 & OH8245 & 48.59 & 45.34 & 37.34 \\
\hline \multicolumn{5}{|l|}{ Controls } \\
\hline \multicolumn{2}{|l|}{ IBL2349 } & 38.70 & 39.80 & 34.73 \\
\hline \multicolumn{2}{|c|}{ Heinz $9423\left(\operatorname{og}^{c}\right)$} & 40.55 & 42.87 & 40.52 \\
\hline \multicolumn{2}{|l|}{ OH8245 } & 45.89 & 44.27 & 38.39 \\
\hline \multicolumn{2}{|l|}{$\operatorname{LSD}_{(0.05)}$} & 2.71 & 1.28 & 1.13 \\
\hline
\end{tabular}

${ }^{2}$ Markers are indicated with their chromosomal location in parenthesis. Alleles are indicated based on the genotype of origin in the pedigree.

yGenotypes combining the Ohio 8245 allele at chromosome 4 and the LA407 allele (IBL 2349) at chromosome 11 were not selected as extreme.

allele of the positive QTL from L. esculentum detected in populations derived from IBL 2349. The observation that many QTL were not shared between the two populations may be explained by the effect of different $L$. hirsutum alleles, different $L$. esculentum backgrounds, different environmental conditions, differences in methods used in phenotypic evaluation, or the small population size and the limited molecular marker coverage of the LA407 IBC population.

Putative QTLassociated with tomato color in either L. hirsutum introgression population were not found in the best lines from the LA407 IBC. In our analysis, the genetic contribution from the wild species was predominantly to shift the population toward undesirable color. Despite the trend of L. hirsutum introgressions to have a negative effect on color, the performance of individual IBLs did suggest some potential in the LA 407 IBC population for the improvement of color as several introgression lines performed as well as commercial checks possessing the $o g^{c}$ allele. Additional studies to identify the loci that contribute to the improvement of tomato color seemed warranted using the best IBLs.

The existence of useful genetic variation for color was confirmed in the population derived from crossing IBL 2349 and Ohio 8245. In the single marker-trait analysis, variation associated with the improvement of red tomato fruit was attributed to two independent QTL from L. esculentum varieties Hunt 100 and Ohio 8245. The variety Hunt 100 contributed a QTL on chromosome 11 that improved color by reducing hue and $\mathrm{L}$ values. Ohio 8245 contributed a QTL on chromosome 4 that increased color by increasing chroma. The interaction of loci appears to be important to the expression of color. Tests of epistasis between the locus on chromosome 4 and the locus on chromosome 11 revealed a significant interaction for hue, L, and chroma. An interesting finding was the detection of significant epistasis of each L. esculentum locus with the chromosome 7 introgression from L. hirsutum LA407. When loci from L. esculentum and the introgressed region of chromosome 7 are homozygous, hue, L, and chroma values positively improve. It is likely that the interaction between QTL on chromosome 11 and 7 explain why IBL 2349 had superior color.

Confirmation of marker-QTL association was obtained by evaluating selected $F_{3}$ and $F_{4}$ progeny within and across environments. Realized heritability estimates based on phenotypic selection ranged from 0.48 to 0.76 . We observed significant location and location $\times$ genotype interactions for chroma and significant location $\times$ marker interaction for the locus on chromosome 4 with $\mathrm{L}$ and chroma. These findings are consistent with our observations in the LA407 IBC population and may reflect variation caused by environmental or nongenetic factors. We attribute these interactions to the prevalence YSD in tomatoes grown on the research farm in Fremont, Ohio as the yellow or green tissue sectors associated with the physiological disorder influence measurements of color. Total phenotypic variation of hue, L, and chroma explained by the locus on chromosome 4 ranged from $14 \%$ to $80 \%$ and by the locus on chromosome 11 from $25 \%$ to $44 \%$ within and across environments.

In conclusion, two independent L. esculentum QTL associated with the improvement of tomato color and linked to markers on 
chromosome 4 and chromosome 11 were identified. These QTL may provide alternative genes for use in breeding programs as a compliment to the old gold crimson $(o g c)$ and the high pigment genes (dg, $h p-1$ and $h p-2)$. It is also encouraging that useful variation for the improvement of red-fruited tomatoes within $L$. esculentum exits.

\section{Literature Cited}

Bernacchi, D., T. Beck-Bunn, J. Eshed, J. Lopez, V. Petriard, J. Uhlig, D. Zamir, and S.D. Tanksley. 1998. Advanced backcross QTL analysis of tomato. I. Identification of QTLs for traits of agronomic importance from Lycopersicon hirsutum. Theor. Appl. Genet. 97:381-397.

Berry, S.Z. and W.A. Gould. 1991. 'Ohio 8245 ' processing tomato. HortScience 26:1093.

Berry, S.Z., K.L. Wiese, and W.A. Gould. 1992. 'Ohio 7983'processing tomato HortScience. 27:939.

Chen, F.Q., M.R. Foolad, J. Hyman, D.A. St.Clair, and R.B. Beelaman. 1999. Mapping of QTLs for lycopene and other fruit traits in a Lycoperiscon esculentum $\mathrm{x}$ L. pimpinellifolium cross and comparison of QTLs across tomato species. Mol. Breeding 5:283-299.

Commission Internationale de l'Eclairage. 1978. Recommendations on uniform color spaces: Color-difference equations, psychometric color terms. CIE, Paris. Publ. 15 Suppl. 2.

Eshed, Y. and D. Zamir. 1995. An introgression line population of Lycoperison pennellii in the cultivated tomato enables the indentification and fine mapping of yield-associated QTL. Genetics 141:1147-1162.

Eskridge, K.M. and D.P. Coyne. 1996. Estimating and testing hypotheses about the number of genes using inbred backcross data. J. Hered. 87:410-412.

Fehr, W.R. 1993. Principles of cultivar development: theory and technique. Iowa State Univ., Ames.

Francis, D.M., T.S. Aldrich, S.Z. Berry, K.L. Scaife, B.S. Schult, and W.D. Bash. 1995. Evaluation of processing tomato breeding lines and cultivars for mechanical harvesting and quality in 1995. Ser. 648. Dept. Hort. Crop Sci., Ohio State Univ., OARDC, Wooster.

Francis, D.M., S.A. Barringer, and R.E. Whitmoyer. 2000. Ultrastructural characterization of yellow shoulder disorder in a uniform ripening tomato genotype. HortScience 35:1114-1117.

Fulton, T.M., T. Beck-Bunn, D.Emmatty, Y.Eshed, J.Lopez, V.Petriard,J. Uhlig, D. Zamir, and S.D. Tanksley. 1997. QTL analysis of an advanced backcross of Lycopersicon peruvianum to the cultvated tomato and comparisons with QTLs found in other wild species. Theor. Appl. Genet. 95:881-894.

Fulton, T.M., S. Grandillo, T. Beck-Bunn, E. Fridman, A. Frampton, J. Lopez, V. Petriard, J. Uhlig, D. Zamir, and S.D. Tanksley. 2000. Advanced backcross QTL analysis of a Lycopersicon esculentum $\mathrm{x}$ Lycopersicon parviflorum cross. Theor. Appl. Genet. 100:1025-1042.

Gartner, C., W. Stahl, and H. Sies. 1997. Lycopene is more bioavailable from tomato paste than from fresh tomatoes. American Journal of Clinical Nutrition 66:116-122.

Gross, J. 1991. Pigments in vegetables: Chlorophylls and carotenoids. VanNostrand Reinhold, New York, NY.

Jenkins, J.A. and G. Mackinney. 1953. Inheritance of carotenoid differences in the tomato hybrid yellow $\mathrm{X}$ tangerine. Genetics 38:107-115.

Jenkins, J.A. and G. Mackinney. 1955. Carotenoids of the apricot tomato and its hybrids with yellow and tangerine. Genetics 40:715-720.

Kabelka, E. 2001. Discovery and introgression of beneficial loci from Lycopersicon hirsutum, LA407, a wild species of tomato. PhD diss. Hort. Crop Sci., Ohio State Univ.

Kabelka,E.,B.Franchino, and D.M. Francis. 2002. Twoloci from Lycopersicon hirsutum confer resistance to strains of Clavibacter michiganensis subsp. michiganensis. Phytopathology 92:504-510.

Kerr, E.A. 1958. Linkage relations of $g f$. Rpt. Tomato Genet. Coop. 8:21

Khudairi, A.K. 1972. The ripening of tomatoes. Amer Sci. 60:696-707.

Koskitalo, L.N. and D.P. Ormrod. 1972. Effects of sub-optimal ripening temperatures on the color quality and pigment composition of tomato fruit. J. Food Sci. 37:56-59.

Lander, E.S., P. Green, J. Abrahamson, A. Barlow, M.J. Daly, S.E. Lincoln, and L. Newburg. 1987. MAPMAKER: an interactive computer package for constructing primary genetic linkage maps of experimental and natural populations. Genomics 1:174-181.
Lee, C.Y. and R.W. Robinson. 1980. Influence of the crimson gene $\left(\operatorname{og}^{c}\right)$ on vitamin A content in tomato. HortScience 15:260-261.

Levin, I., P. Frankel, N. Gilboa, S. Tanny, and A. Lalazar. 2003. The tomato dark green mutation is a novel allele of the tomato homolog of the DEETIOLATED1 gene. Theor. Appl. Genet. 106:454-60.

Li, Z. 1997. Molecular analysis of epistasis affecting complex traits, p. 119-130. In: A.H. Paterson (ed.). Molecular dissection of complex traits. CRC Press, New York.

Michelmore, R.W., I. Paran, and R.V. Kesseli. 1991. Identification of markers linked to disease-resistance genes by bulked segregant analysis: a rapid method to detect markers in specific genomic regions by using segregating populations. Proc. Natl. Acad. Sci. U.S.A. 88:9828-9832.

Precheur, R.J. 2000. Ohio vegetable production guide. Ohio State Univ. Coop. Ext. Bul. 672.

Rick, C.M. and R.T. Chetelet. 1993. TGRC stock lists. Rpt. Tomato Genet. Coop. 43:53-56.

Ronen, G., L. Carmel-Goren, D. Zamir, and J. Hirshberg. 2000. An alternative pathway to beta-carotene formation in plant chromoplasts discovered by map-based cloning of Beta and old-gold color mutations in tomato. Proc. Natl. Acad. Sci. USA 97:11102-11107.

Sacks E.J. and D.M. Francis. 2001. Genetic and environmental variation for flesh color of tomato fruit in a population of modern breeding lines. J. Amer. Soc. Hort. Sci. 126:221-226.

Stahl, W. and H. Sies. 1996. Perspectives in biochemistry and biophysics: Lycopene: A biologically important carotenoid for humans? Arch. Biochem. Biophys. 336:1-9.

Tanksley, S.D., M.W. Ganal, J.P. Prince, M.C. deVicente, M.W. Bonierbale, P. Broun, T.M. Fulton, J.J. Giovannoni, S. Grandillo, G.B. Martin, R. Messeguer, J.C. Miller, L. Miller, A.H. Paterson, O. Pineda, M.S. Roder, R.A. Wing, W. Wu, and N.D. Young. 1992. High density molecular linkage maps of the tomato and potato genomes. Genetics 132:1141-1160.

Tanksley, S.D. and J.C. Nelson. 1996. Advanced backcross QTL analysis: A method for the simultaneous discovery and transfer of valuable QTLs from unadapted germplasm into elite breeding lines. Theor. Appl. Genet. 92:191-203.

Tanksley, S.D., S. Grandillo, T.M. Fulton, D. Zamir, Y. Eshed, V. Petiard, J. Lopez, and T. Beck-Bunn. 1996. Advanced backcross QTL analysis in a cross between an elite processing line of tomato and its wild relative $L$. pimpinellifolium. Theor. Appl. Genet. 92:213-224.

Thompson, A.E., M.L. Tomes, E.V. Wann, J.P. McCollum, and A.K. Stoner. 1965. Characterization of crimson tomato fruit color. Proc. Amer. Soc. Hort Sci. 86:610-616.

Thompson, A.E., M.L. Tomes, H.T. Erickson, E.V. Wann, and R.J. Armstrong. 1967. Inheritance of crimson fruit color in tomatoes. Proc. Amer. Soc. Hort. Sci. 91:495-504.

Tomes, M.L., F.W. Quackenbush, O.E. Nelson Jr., and B. North. 1953. The inheritance of carotenoid pigment systems in the tomato. Genetics 38: $117-127$.

Tomes, M.L., F.W. Quackenbush, and T.E. Kargl. 1956. Action of the gene B in biosynthesis of carotenes in the tomato. Bot. Gaz. 117:248-253.

Van der Knaap, E. and S.D. Tanksley. 2001. Identification and characterization of a novel locus controlling early fruit development in tomato. Theor. Appl. Genet. 103:353-358.

VanTuinen,A., M.M. Cordonnier-Pratt, L.H.Pratt, R. Verkerk,P.Zabel, and M. Koorneef. 1997. The mapping of phytochrome genes and photomorphogenic mutants of tomato. Theor. Appl. Genet. 94:115-122.

Wann, E.V. 1997. Tomato germplasm lines T4065, T4099, T5019, and T5020 with unique genotypes that enhance fruit quality. HortScience 32: 747-748

Yang, W., X. Bai, C. Eaton, S. Kamoun, E. van der Knaap, and D. Francis, D. 2003. Discovery, mapping, and application of single nucleotide polymorphisms in Lycopersicon esculentum. Intl. Conf. Status of Plant and Animal Genome Res., PAG XI, P247, p. 136.

Yen, H., A. Shelton, L. Howard, J. Vrebalov, and J. Giovannoni. 1997. The tomatohigh-pigment (hp) locus maps to chromosome 2 and influences plastome copy number and fruit quality. Theor. Appl. Genet. 95:1069-1079.

Young, P.A. 1956. ry, A modifier gene for red color in yellow tomato fruit. Rpt. Tomato Genet. Coop. 6:33.

Wing, R.A., H.B. Zhang, and S.D. Tanksley. 1994. Map-based cloning in crop plants. Tomato as a model system. Genetic and physical mapping of jointless. Mol. Gen. Genet. 242:681-688. 